\title{
The Effectiveness of Designing and Using a Practical Interactive Lesson based on ADDIE Model to Enhance Students' Learning Performances in University of Tabuk
}

\author{
Sameer Mosa Alnajdi ${ }^{1}$ \\ ${ }^{1}$ Assistant Professor of Education Technology, Faculty of Education and Arts, University of Tabuk, Saudi Arabia \\ Correspondence: Sameer Mosa Alnajdi, Faculty of Education and Arts, University of Tabuk, Tabuk, Saudi Arabia. \\ Tel: 966-59-777-9019.
}

Received: September 10, 2018

Accepted: October 6, $2018 \quad$ Online Published: November 6, 2018

doi:10.5539/jel.v7n6p212

URL: https://doi.org/10.5539/jel.v7n6p212

\begin{abstract}
Traditional teaching is one of the most common types of education, but with the explosive technologies, Traditional teaching could not be effective. Therefore, adopting and utilizing computer and communication technology in education became most important to make the learning more active, but before utilizing technology in education, instructors need to ensure of suiting the technology with the students' abilities and characteristics based on Instructional design models, With the tremendous development of technology and the enhancement of student performance. In this paper, an interactive lesson designed based on ADDIE Model. Students divided into two groups; a control group and experimental group each group had 36 students to evaluate the effectiveness of using the interactive lesson and its role in enhancing students' Learning Performance. The lesson had several stages; starting from having a useful design based on ADDIE Model, then provided a demo to the students to understand the knowledge. After that, the lesson presented in an interactive way, assistance's hints provided to students during their learning process and reviewing the initial demo was available for the whole lesson. The effectiveness of this design has been measured, and results in both groups in this study compared, the experimental group showed statistically significant on students' performances with a mean score of 5.45 versus 4.24 for the control group.
\end{abstract}

Keywords: instructional design, ADDIE model, interactive learning, students' performance

\section{Introduction}

\subsection{Introduce the Problem}

Students in this era has many different characters than the last two eras, they have been growing with technology and this technology became part of their daily life, but some schools take them back to the last century by using traditional ways of teaching by focusing on teacher-centered learning, which teachers manage and deliver knowledge to students, and the only role for students is receive knowledge and memorize it "The educational system may need to utilize and compete with the new Information and communication technologies and benefit from them. There are lots of possibilities of such utilization" (Nusir et al., 2011, p. 49). In addition, using practical interactive learning will help students of special needs and disabilities. According to (Nusir et al., 2011, p. 49) "Students who have visual, or hearing problems may not be able to see or hear well the class material especially when class size is large." However, schools and colleges should adopt a new way of teaching, which make their students enjoying the lesson and more active, Nusir et al. (2011) were reported "new technologies can provide a solution to this problem by recording different teacher courses or through an e-learning system. A new interactive educational system may provide solutions to the problems in the traditional educational systems" ( $p$. 49). However, to ensure students involved in the learning process instructors and teachers need to use effective way to encourage students and catch their attention by use new way of teaching and change their environment and their role from teacher-centered learning environment to student-centered learning environment and their role from only receivers to active students, which, utilizing technology in education became most important to make the learning more active, (Hoidn, 2017; Nozari \& Siamian, 2015). Student-centered learning "students become the center of the learning process by influencing the content, activities, materials, and pace of learning. If properly implemented, the SCI approach strengthens retention of knowledge and increases motivation to learn" 
(Collins \& O’Brien, 2003, p. 446).

In addition, there is a necessary step need to be done before utilizing technology in education, instructors to ensure of technologies are suiting with the students' abilities and characteristics, this step is checking the Instructional design models before building an instruction or adoption fit with students and doing their roles correctly by design in the instruction or choose the technology based on one if the instructional design models, such as ADDIE and ASSURE; these models draw the whole picture and make the view more clear and effect before and during building the design, and choose the right and effective tool or program to build and deliver the interactive lesson. Adopting technology in any class could be in many ways, but in the student-centered learning, this adopting has to make students more active in the class. In this paper, the lesson has been built based on two elements; the first one is the theoretical element, which based on ADDIE model and the second one based on Adobe Captivate the practical element to build the interactive multimedia easily to enhance students' learning performance (Branch, 2010; Zhang et al., 2006).

\subsection{Purpose and Significance of the Study}

The purpose of this study was to investigate if there is an effect of using a practical interactive lesson has been designed based on instructional design models and used Adobe Captivate to find the effectiveness of the design lesson on students' performance and comparing the results between pre-test and post-test for both groups and find the value of using the interactive lesson of making the learning easily and quickly.

\section{Literature Review}

\subsection{Interactive Learning}

The interactive learning is defined by involving students in effective learning activities by adopting more technologies beyond the traditional learning boundaries with predominately interactive learning environments to help students to achieve a higher level of learning and enhancing their learning performance (Tchoshanov, 2013). Instructors can create an interactive learning environment in many ways, but the most comments are to use Computers to present the interactive learning, according to Selinger (2001):

Computers can present information in ways in which teachers are unable; they can present information in multimedia formats allowing users to select and experience new knowledge in a text, graphics, sounds or video; make use of hyperlinks to link concepts together. It allows the [student] to make choices about the medium through which they learn and present them with a wide range of hitherto unimaginable resources. (p. 5)

In addition, by reviewing many of studies over the years, such as Merkt et al., 2011; Sariscsany \& Pettigrew, 1997; Schwan \& Riempp, 2004; Zhang et al., 2006; Nozari \& Siamian, 2015; Teye, 2011; Nusir et al., 2011) have shown that students' performances have been raised and became more enjoyable based on use interactive learning and were more successful than non-interactive students group. According to Najjar "learning was higher when information was presented via computer-based multimedia systems than traditional classroom lectures" (1996, p. 30), interactive learning environment offers to students the opportunities to increase their self-directed and develop their performance (Zhang et al., 2006). Interactive learning is a strategy that attempts to provide spaces committed to purposeful learning in a way that follows the spaces in which students will achieve information and knowledge that have been learned, in a study applied in Jourdan the researchers found "interactive enhanced learning can provide a very useful alternative for traditional education especially in cases where it is not applicable to teach through traditional methods" (Nusir et al., 2011, p. 50). The ADDIE model applied to instructional design provides a way to address the complexities associated with learning space (Branch, 2010). Interactive learning to be more effective needs to design in the right way to achieve the lesson outcomes and make the lesson more effective. (Holzinger et al., 2009) study addressed the effects of using interactive learning lesson by using simulation to teach 96 medicine students a physiological model, they used three ways to teach their students; traditional way, interactive way, and interactive way with combination of additional material and support. In the results they found students in the first two way had the same result, however, the last way when they used additional materials with the interactive lesson conceded a significantly higher learning performance. The increasing of technologies has made implementing technologies and designing interactive learning system a basic requirement in the education system to ensure students not be behind in their schools because they are living in the technologies world and made a significant impact on the evolvement of teaching methods from traditional face-to-face teaching to interactive learning. It is additionally expected that the future will see a greater amount of the usage of new ways of interactive learning ways. They concluded that interactive lesson can be effective but "the inclusion of pedagogical and psychological expertise into the design and development of educational software is essential" (p. 1), which shows any design should to build based on educational background based on instructional design models to from the begging to students' needs. However, 
the lesson need to be design based in instructional design models to ensure the interactive lesson designed in the effective way, one of these models is ADDIE.

\subsection{ADDIE Model}

According to (Branch, 2010) instructional design is a methodical process that is utilized to create training and preparing programs in a steady and solid form. In any case, the instructional design is a perplexing process that is inventive, interactive, and dynamic. Instructional design models enable designers and teachers to visualize the whole picture of the design's process to build up rules for overseeing instructional design processes, "Instructional design is characterized as learner-centered, goal oriented, focusing on meaningful performance, assuming that outcomes can be measured, procedures are based on empirical evidence, interactive, self-correcting, and typically a team effort" (Branch, 2010, p. 10). Instructional design has many models built to use when designers want to design their instruction, one of these models is ADDIE model. ADDIE model has its development tracing back to the 1970s by Florida State University's Center for Educational Technology for the US Army for education reasons. ADDIE is an abbreviation for the five phases in the order of analysis, then design and development, implementation and the last phase is evaluation, but it has role during each stage to ensure of rising, developing, and rebuilding the design (ADDIE Model-Training Industry, 2018) these phases work on order to ensure the design run perfectly (see Figure 1). "The ADDIE process facilitates the ability of intentional learning modules to progress the student while increasing the fidelity between the learning space and the performance space, thereby increasing the potential for success" (Branch, 2010, p. 10), instructional design advances high reliability between learning environments and real work settings. High fidelity among learning and work environments is achieved by instructional design through an emphasis on measurable outcomes.

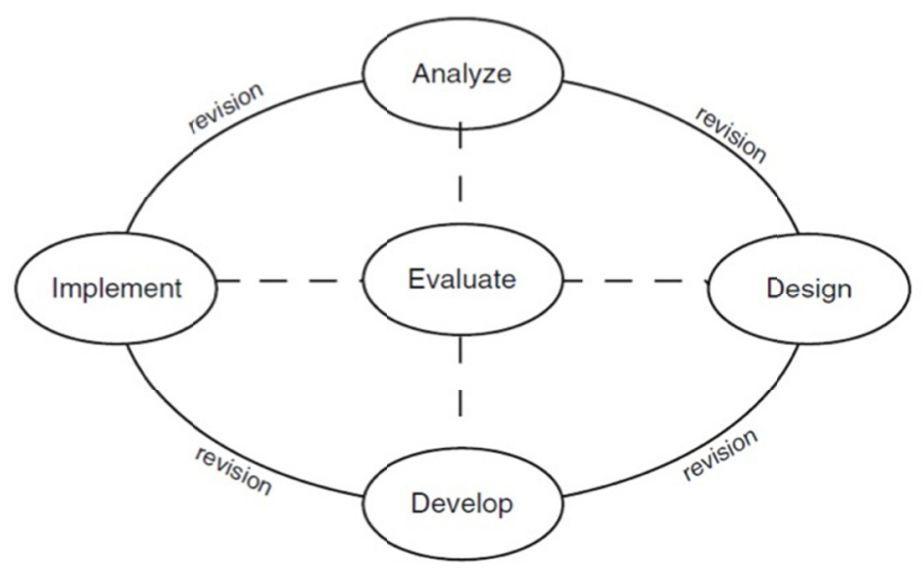

Figure 1. The ADDIE concept

The system has been employed to ensure compliance training and time insensitive learning. It is largely flexible as the phases are easily modified to suit the needs of the user; ADDIE's phases implement an input, process, and output (IPO) paradigm as a way to complete the process the design. The result of implementing an IPO paradigm is a layered synchronized way to deal with the ADDIE phases, ADDIE is setting delicate, proactive, intelligent and is a vehicle for conveying thoughts to all partners.

ADDIE is orderly since it builds up guidelines and systems, and also the convention for setting up the principles and methodology and constitutes dependable ways to deal with planning direction (See Figure 2). ADDIE is fundamental since all components of the process react to any stimulus, and using instructional design model, such as ADDIE helps to avoid complexities during design any instruction (Branch, 2010). Therefore, using instructional design models are important for having fit teaching methods with students and available equipment for teaching activities to eradicate weaknesses in traditional instruction and increase the learning impact. "Learning psychologists usually suggest that teaching materials should be presented with various methods so that students with different learning styles could acquire knowledge through distinct senses" (Ismail, 2018, p. 15). According to Molenda, Reigeluth, and Nelson instruction design (ID) refers to "the principles and procedures by which instructional materials, lessons, and whole systems can be developed in a consistent and reliable fashion" (as cited in Hess \& Greer, 2016, p. 266). 


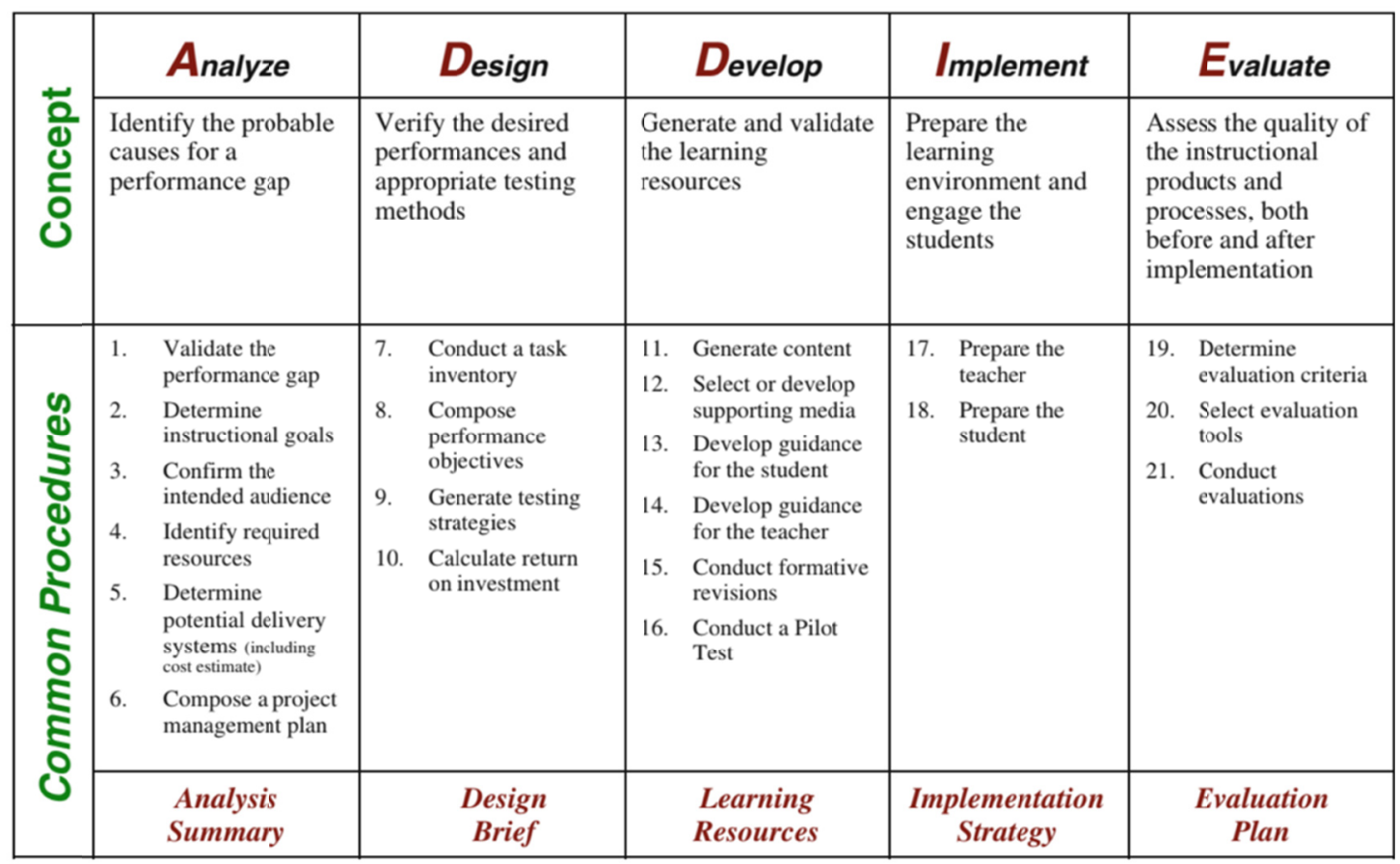

Figure 2. ADDIE model phases and process (Branch, 2010)

\subsection{Adobe Captivate}

Adobe Captivate is an electronic learning application for authoring According to (Pather et al., 2016, prog 1) "Adobe Captivate is an eLearning authoring software that allows its user to create, design and rebuild engaging and interactive eLearning content from storyboarding to responsive eLearning design, for multi-devices including desktop, tablet, mobile and the web." It allows a designer to create, design and rebuild engagements. Interactive content on the electronic learning platform is directed from a storyboard to responsive design for many environments (Pather et al., 2016). It has been an important technology in the creation of live interactive and collaborative learning. New actors can be added into interactions and quizzes by the use of new user crossing point. Tests used to examine the knowledge, training needs and level of skills of the students evaluate and track the performance of the students (Pather et al., 2016). This made possible supplementary evaluation through assessments developed from Adobe Captivate customized templates and random pool selection questions. Adobe Captivate has been used to create interactive building blocks online. For instance, it was utilized in Lymphoma and Leukemia interactive online modules for medical students in the senior study stage between 2007 and 2009 These interactive modules had significantly affected understudies' adapting, most likely due to in-assembled interactivity, feedback, genuine contextual investigations and incorporation with the curriculum and learning modules. All that, make Adobe Captivate useful technology for:

- Making live and self-managed intelligent and helpful on-line learning courses.

- Making modules that might be gotten to whenever wherever and on any gadget.

- Making pre-tests to gauge the information, aptitudes levels or instructing needs of researchers.

Assessing and finishing student execution appraisals that might be produced from adjustable test layouts and arbitrary inquiry pool decision (Pather et al., 2016).

The impact on students' learning was remarkable. This is attributed to the inherent interaction ability, feedback program, and integration with the study program. It was used mainly due to taking part in PowerPoint, video and quiz interactions. Learners' preparation will involve training on the use of the applications and registering them to the interactive lessons. Connecting with a community of Adobe Captivate users would be appropriate as to enable newly registered learners to share their best practices. Preparation of learning materials should take place at this juncture and test the interacting platforms. Finally, evaluation ensures that all the targets made at the beginning of the process will meet the needs specified (ADDIE Model-Training Industry, 2018). Pather et al., 2016 listed benefits of Adobe Captivate, such as: 
- Convey and offer multiscreen.

- Creating pleasant interactive simulations.

- Can tweak screens.

- Can utilize activity contents to make greater intuitiveness.

- Can recordings screen.

- Can include web objects.

- Can include web objects.

- Can incorporate testing, problem areas, YouTube recordings.

Sharing own designed project made with Adobe Captivate is to take place next. At this point, we need to ensure that all the project needs are met to the complete end. Adobe Captivate has been effective in the delivery and the active distribution of learning experiences. This has been achieved for location-specific sharing among multiple screens in a device aware fashion without necessarily depending on programming techniques. The interactive lesson designed based on Adobe Captivate successfully created engaging interactive sessions (Ghirardini, 2011). It contributed largely to the better performance of the students as used in lymphoma and leukemia interactive online modules to facilitate the learning for medical students in senior study stage (Pather et al., 2016). The emergence of e-learning technologies and the existence of the electronic learning interaction programs have had an intense and immediate transformation of the education systems. It is argued that it has played a crucial role in response to the global competition and increased quality of learning experiences (Anderson, 2008).

\section{Methodology}

\subsection{Research Question}

To achieve Purpose and Significance of the study, this study will answer the following question:

Does using practical interactive lesson based on ADDIE model enhance students' learning performance?

\subsection{Null Hypothesis}

To answer the study's question in the right way, the study needs to check these two hypotheses, to ensure the effectiveness of using the practical interactive lesson:

1) There are no statistically significant differences in pre-test for the control and experimental groups in students' performances.

2) There are no statistically significant differences between the control and experimental groups in students' performances based on using the practical interactive lesson.

\subsection{Limitation}

This study has a limitation of students by focusing on freshmen students who attended Communication College because these students have lower GPA in their High-schools Diploma. The study has been applied in the second semester of the Academic year 2018 at University of Tabuk. In addition, another limitation was the course selected; Foundation Course of Computer Skills, specific to Excel Unit.

\subsection{Designing the Experiment}

The lesson has been designed based on two ways; theoretical way, which designing the lesson based on ADDIE model to ensure the lesson build in the right theoretically way, basing the ideology on the ADDIE model, through its five phases: analysis the students characteristics to choose and design the interactive lesson based on their needs and consistent with students' characteristics. The second phase in ADDIE model is designing the lesson after drawing the whole picture of the lesson, this design counting as a draft because after the design completed the designers run it for checking and reviewing, which is the next phase in ADDIE, development, which designers review the result from the pilot study and their comments and the experts' evaluations to develop the design to make it more professional and stable. In this case, a pilot study of students has been choosing to use the design and some experts have been asked to evaluate the design, this called formative evaluation which is part of the evaluation phase. Elevation phase listed at the end of the ADDIE model, but in fact, it is liberal and effect in all phases, (see Figure 1). After the designers finish the developing phase based on experts' evaluations (5 professors; 2 in the education field and 3 in computer science field) and the pilot study result (7 students) from the design become ready to use and implement the design to actual, this is the implementation phase in ADDIE. The last phase in the model is evaluation, its order became the last one, but it is applying in all the previous phases and evaluation divided into two phases; formative evaluation, which became 
during the design and summative evaluation, which evaluate the implementation of the design and measuring its effect by to find the effective of using the interactive lesson to enhance students' learning performance (Branch, 2010). Second way of the designing the experiment is the technical way, which built based in Adobe Captivate to transfer the design in real lesson to design and use a practical interactive lesson and the procedure is facilitated by Adobe Captivate to enhance students' learning performance in three sections; the first provided a demo to the students to understand the knowledge and provide a brief view of Microsoft Excel as a part of Microsoft applications, the second section is the lesson presented in in an interactive way, assistance's hints provided to students during their learning process and reviewing the initial demo was available for the whole lesson, which guide the students on each step of using Excel and explaining its functions (see Figure 3), the last section in the interactive lesson is the assessment part to measure students' performances of using the interactive lesson (see Figure 4), and testing the effectiveness of the design to determine the level of performance and satisfaction level of the results (Horton, 2011).

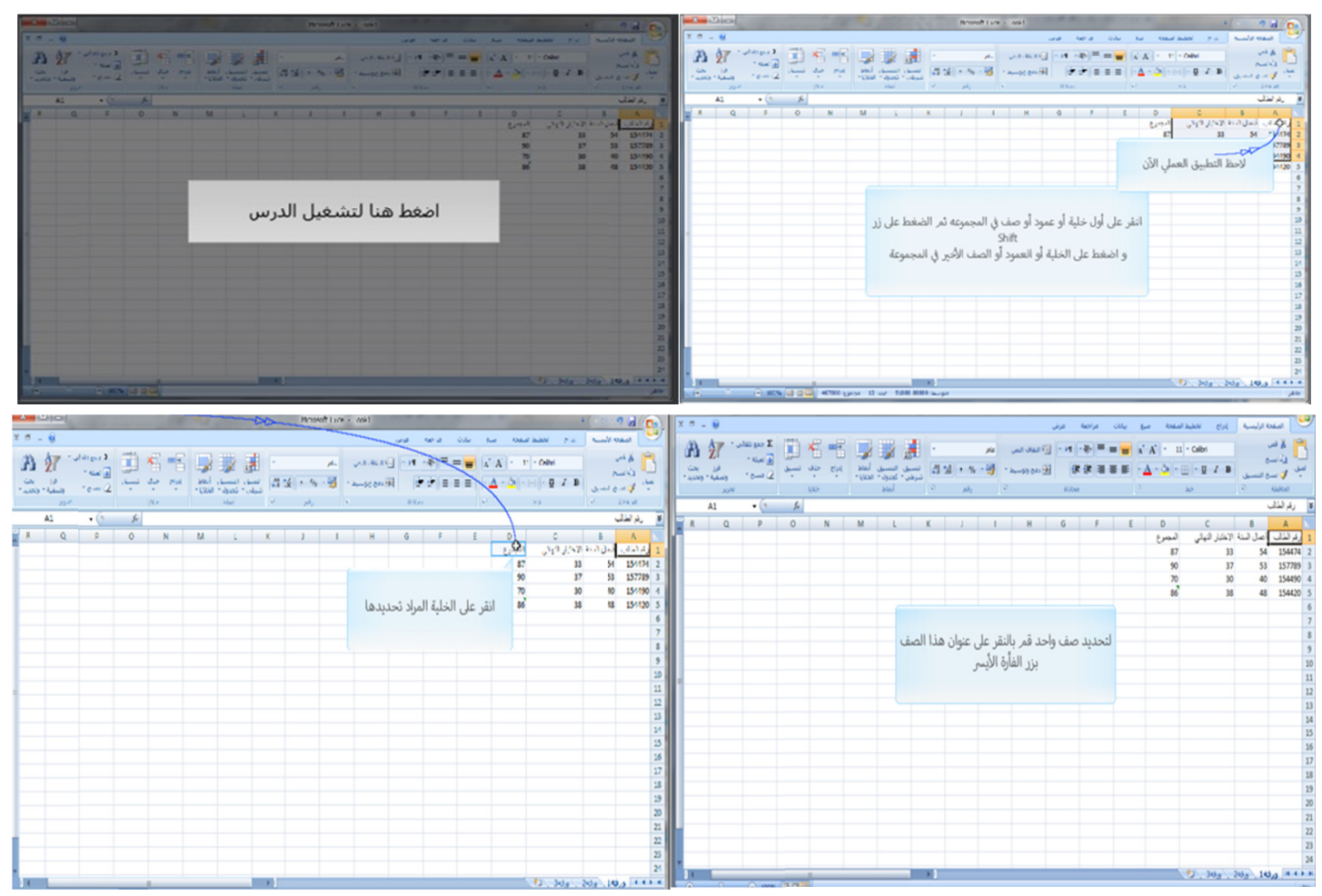

Figure 3. Screenshot of the interactive lesson 

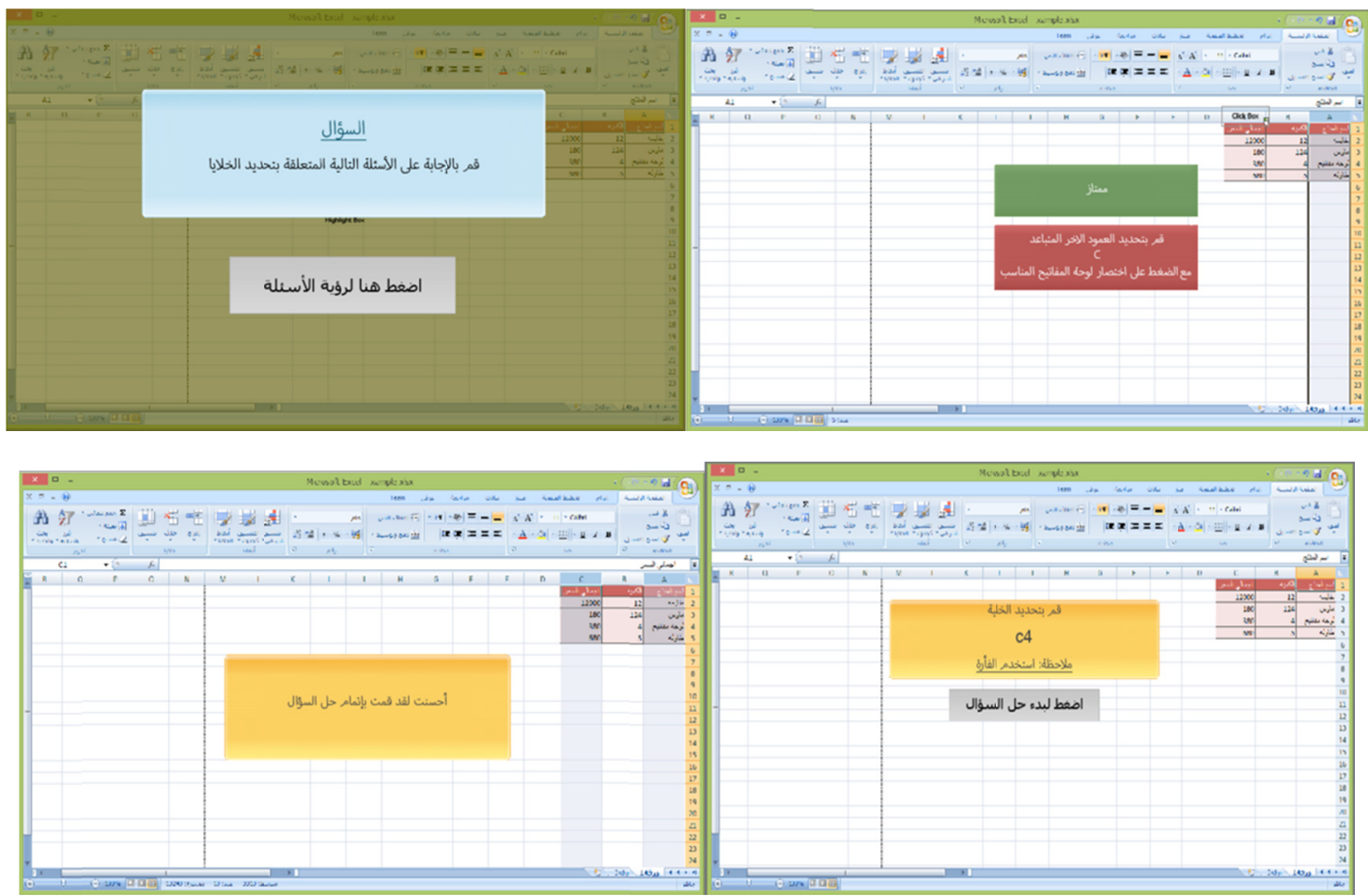

Figure 4. Screenshot of the assessments

\subsection{Sampling Procedures}

A total of 70 male freshmen students in the Community College in University of Tabuk participate in this study, these participants are representing two classes of foundation CS class, these participants divided into two groups; control group and experimental group, each group has 35 students, these are taking the course in the same semester, with the same instructor, in the second semester of the academic year 2018. The instructor used the practical interactive lesson with the experimental group and used the traditional teaching way with the control group, both groups take four weeks; represented in three meeting class during each week; three hours for each class to finish the unit, pre-test and post-test have been applied for the two groups.

\section{Results}

Data run in SPSS to analyze the data and answer the research questions, T-test used to analyze the collected data to find out the results of this study. The findings have been appealed from the begging of the class, after students had the pre-test, which showed a little different in pre-test for the control and experimental groups in students' performances, but this difference was only 0.03 higher in the mean score for the experimental group, but this different is not statically significant, for that this difference has no statically meaning. Therefore, the first null hypothesis "There are no statistically significant differences in pre-test for the control and experimental groups in students' performances" was not rejected, and the conclusion made that there was no significant difference in students' performances based on the pre-test for both control and experimental groups, which give an indicator that both groups in the same level of understanding and knowing Excel (see Table 1), which indicated that, the deference of the students performances based in the teaching methods used to deliver the knowledge and information during the semester.

Table 1. Result of t-test of the pre-test between both groups

\begin{tabular}{lccccc}
\hline & $\mathrm{n}$ & $\mathrm{M}$ & $\mathrm{SD}$ & T-test & Sig. \\
\hline Control group & 36 & 1.79 & .74 & \multirow{2}{*}{.16} & .87 \\
Experiment group & 36 & 1.82 & .81 & \multirow{2}{*}{} \\
\hline
\end{tabular}

* Significant at the $\mathrm{p} \leq 0.05$ probability level, $\mathrm{S}=$ Significance. 
In addition, after the lesson has been delivered in both ways; traditional teaching and practical interactive, a post-test has been presented to both groups to find out the development of students' performances and measure the effectiveness of using the practical interactive lesson, the results showed there are improving in the students' performances in both groups from the pre-test and post-test, and the experiment group had higher improving in the mean score of students' performances (see Table 2).

Table 2. Mean scores of the pre-test and post-test for both groups

\begin{tabular}{lcccc}
\hline & $\mathrm{n}$ & Test & $\mathrm{M}$ & $\mathrm{SD}$ \\
\hline \multirow{2}{*}{ Control group } & \multirow{2}{*}{36} & Pre-test & 1.79 & .74 \\
& & Post-test & 4.24 & .90 \\
\multirow{2}{*}{ Experiment group } & \multirow{2}{*}{36} & Pre-test & 1.82 & .81 \\
& & Post-test & 5.45 & 1.00 \\
\hline
\end{tabular}

Furthermore, after results showed improved in the students' performances in both groups, and this improved was higher in the experimental group by 1.21 in the mean score, testing this improve necessary to check it is a significate improving or not, the result showed that, the students' performances during used the practical interactive lesson had higher mean score and this difference was significant differences, which means using the designed practical interactive lesson has higher impact of developing and improving students' performances (see Table 3).

Table 3. Result of t-test of post-test between experimental group and control group

\begin{tabular}{lccccc}
\hline & $\mathrm{n}$ & $\mathrm{M}$ & $\mathrm{SD}$ & T-test & Sig. \\
\hline Control group & 36 & 4.24 & .90 & \multirow{2}{*}{$5.16^{*}$} & \multirow{2}{*}{0.00} \\
Experimental group & 36 & 5.45 & 1.00 & & \\
\hline
\end{tabular}

* Significant at the $\mathrm{p} \leq 0.05$ probability level, $\mathrm{S}=$ Significance.

\section{Discussion and Conclusion}

This study was designed to find out the improving and developing of students' performances toward designing and using practical interactive lesson based on ADDIE model. The main question was asked to find that out. In addition, two hypotheses were used to answer the study's question; these hypotheses had been tested through T-test to check its results, the first hypothesis was to find out students' performances and to check out there were in the same stage of the unit before running through the course, and the second one to figured out the effectiveness of using the practical interactive lesson on students' performances. Founding there are no statistically significant differences in pre-test for the control and experimental groups in students' performances, mean the two groups were equal and students in these groups had the same level of the information and knowledge about Excel, which makes the study stronger by ensuring the only variable has the effectiveness. However, after tested the results of pre-test and post-test for both groups and found the t-test for them to check the signification the results proved the two lessons had been positively effective to improve and develop students' performances toward learning Excel, and statically approved the practical interactive lesson has higher impact than the traditional teaching method, which answered the study's question "does using practical interactive lesson based on ADDIE model enhance students' learning performance?" which shown and approved that, students' performances had been effective positively based on used a well-designed practical interactive lesson. For instance, this result agreed with many studies, such as Merkt et al., 2011; Sariscsany \& Pettigrew, 1997; Schwan \& Riempp, 2004; Zhang et al., 2006; Nozari \& Siamian, 2015; Teye, 2011; Nusir et al., 2011), it has been used on lymphoma and leukemia interactive online modules to facilitate the learning for medical students in senior study stage between 2007 and 2009 (Pather et al., 2016). The impact on students' learning was remarkable. This level of success of the design is attributed to the inherent interaction ability.

Based on the results of the study, the researcher can conclude that using different methods of teaching are useful, even the traditional method, but adopting practical interactive teaching will promote students' knowledge and performances and increase them to be more active and cooperating with their peer, therefore, both methods should be considered in teaching students, but with focusing on the interactive method in order to improve learning preferences and to suit different learning experiences of students. In addition, ADDIE models are flexible and build effective training and, subsequently, the performance of students, based on the experts' reviews. The 
effectiveness of the design can be examined to determine the level of performance and satisfaction level of the results (Horton, 2011). The practical interactive lesson had been designed in accordance with the ADDIE model have a more effective learning and better performances of students rather than traditional teaching way. The impact on students' learning was remarkable and the success is attributed to the inherent interaction ability, feedback program, and integration with the study program. In the effort to make it more effective and improve students' performance, the effectiveness of the Adobe Captivate based on the ADDIE model will be evident from many perspectives. This will be reflected in the performance of the tests issued for assessment of the understanding by the students, and one of the most impacted points has been showed and recorded by the instructor; students became more active and more cooperation with their peer in the practical interactive lesson. In addition, an open question provided to students who were in the experiment group and controller group about their perceptions of methods of delivering the lesson at the end of the lesson. students in the experimental group were very excited about the interactive lesson and they felt it is touching their need and it is designed exactly for them because they did not feel behind, and the design gave them the chance to have exercising at home and to review the lesson much time as they want to get all points clear and easy. In another hand, students took the traditional lesson said they had a hard time to understand the whole lesson especially when they had to miss the class or became late, in addition, some difficult parts to understand, and they have to meet the instructor in class to ask about the un-understandable points.

\section{Acknowledgments}

I am indebted to the Scientific Research Deanship in University of Tabuk for granting this study under grant number by No. S-0055-1439, and to thanks; doctors Malik Alrashidi and Khalid almohamamadi from the Computer Science Depart.

\section{References}

ADDIE Model-Training Industry. (2018). Training industry. Retrieved from https://trainingindustry.com/wiki/addie -model/?utm_content=cpdc

Anderson, T. (2008). The theory and practice of online learning. Athabasca: Athabasca University Press.

Branch, R. (2010). Instructional Design: The ADDIE Approach. Boston, MA: Springer US.

Culatta, R. (2013). ADDIE Model. Retrieved from http://www.instructionaldesign.org/models/addie.html

Ghirardini, B. (2011). E-learning methodologies: A guide for designing and developing e-learning courses. Rome: Food and Agriculture Organization of the United Nations.

Hess, A. N., \& Greer, K. (2016). Designing for Engagement: Using the ADDIE Model to Integrate High-Impact Practices into an Online Information Literacy Course. Comminfolit, 10(2), 264-282. https://doi.org/10.15760/comminfolit.2016.10.2.27

Hoidn, S. (2017). Student-centered learning environments in higher education classrooms. Springer. https://doi.org/10.1057/978-1-349-94941-0

Holzinger, A., Kickmeier-Rust, M.D., Wassertheurer, S., \& Hessinger, M. (2009). Learning performance with interactive simulations in medical education: Lessons learned from results of learning complex physiological models with the HAEMOdynamics SIMulator. Computers \& Education, 52, 292-301. https://doi.org/10.1016/j.compedu.2008.08.008

Horton, W. (2011). e-Learning by design. Hoboken, NJ: John Wiley \& Sons. https://doi.org/10.1002/9781118256039

Ismail, L. M. N. (2018). Effect of instructional multimedia methods on learning outcomes among nursing students in selected topic of health assessment. International Academic Journal of Health, Medicine and Nursing, 1(2), 11-29

Merkt, M., Weigand, S., Heier, A., \& Schwan, S. (2011). Learning with videos vs. learning with print: The role of interactive features. Learning and Instruction, 21(6), 687-704. https://doi.org/10.1016/j.learninstruc.2011.03.004

Najjar, L. J. (1996). The effects of multimedia and elaborative encoding on learning. Graphics, Visualization \& Usability Center, Georgia Institute of Technology Press

Nozari, Y. A., \& Siamian, H. (2015) The Effect of Applying Podcast Multimedia Teaching System on Motivational Achievement and Learning Among the Boy Students. ACTA Inform, 23(1), 23-29. https://doi.org/10.5455/aim.2015.23.29-32 
Nusir, S., Alsmadi, I., Al-Kabi, M., \& Shardqah, F. (2011). Designing an interactive multimedia learning system for the children of primary schools in Jordan. 2011 IEEE Global Engineering Education Conference, EDUCON 2011, 45-51. https://doi.org/10.1109/EDUCON.2011.5773111

Pather, N., Azouz, L., Velan, G., \& Vickery, R. (2016). Adobe Captivate| Teaching technology toolkit. Retrieved from https://teachingtools.med.unsw.edu.au/tool/adobe-captivate

Sariscsany, M. J., \& Pettigrew, F. (1997). Effectiveness of interactive video instruction on teacher's classroom management declarative knowledge. Journal of Teaching in Physical Education, 16(2), 229-240. https://doi.org/10.1123/jtpe.16.2.229

Schwan, S., \& Riempp, R. (2004). The cognitive benefits of interactive videos: learning to tie nautical knots. Learning and Instruction, 14(3), 293-305. https://doi.org/10.1016/j.learninstruc.2004.06.005

Selinger, M. (2001) The role of the teacher: teacherless classrooms. In M. Leask (Ed.), Issues in teaching and learning with ICT. London, Routledge

Tchoshanov, M. (2013). Engineering of Learning: Conceptualizing e-Didactics. UNESCO Institute for Information Technologies in Education, Moscow. Retrieved July 22, 2018, from https://iite.unesco.org/pics/publications/ en/files/3214730.pdf

Teye, V. Q. (2011). Developing interactive learning system for teaching the elements of design in Senior High Schools (Unpublished master thesis). Kwame Nkrumah University of Science and Technology, Kumasi, Ghana.

Zhang, D., Zhou, L., Briggs, R., \& Nunamaker, J. (2006). Instructional video in e-learning: Assessing the impact of interactive video on learning effectiveness. Information \& Management, 43(1), 15-27.

\section{Copyrights}

Copyright for this article is retained by the author, with first publication rights granted to the journal.

This is an open-access article distributed under the terms and conditions of the Creative Commons Attribution license (http://creativecommons.org/licenses/by/4.0/). 